\title{
Risk Assessment for Bridges Safety Management during Operation Based on Fuzzy Clustering Algorithm
}

\author{
Hanyu Xia ${ }^{1, a}$, Lijing Zhang ${ }^{1}$, Gang Tao ${ }^{1}$, Bing Tong ${ }^{1}$ and Haiou Zhang ${ }^{2}$ \\ ${ }^{1}$ Jiangsu Key Laboratory of Urban and Industrial Safety, College of Urban Construction and Safety Engineering, Nanjing Tech University, \\ Nanjing, 210009, China; \\ ${ }^{2}$ Nanjing Architectural Design \& Research Institute CO., LTD,Nanjing 210005, China
}

\begin{abstract}
In recent years, large span and large sea-crossing bridges are built, bridges accidents caused by improper operational management occur frequently. In order to explore the better methods for risk assessment of the bridges operation departments, the method based on fuzzy clustering algorithm is selected. Then, the implementation steps of fuzzy clustering algorithm are described, the risk evaluation system is built, and Taizhou Bridge is selected as an example, the quantitation of risk factors is described. After that, the clustering algorithm based on fuzzy equivalence is calculated on MATLAB 2010a. In the last, Taizhou Bridge operation management departments are classified and sorted according to the degree of risk, and the safety situation of operation departments is analyzed.
\end{abstract}

\section{Introduction}

Bridges operation departments are important for bridges safety, because they conduct the regular inspections, testing, maintenance and debugging for the main body of the bridge and the auxiliary road facilities during operation. As the number of large bridges increased, many bridges accidents occur due to the inadequate management, management risk of bridge operation departments has become an important part of phase risk factors which cannot be ignored during operation. Identifying the risk factors of the bridges operation departments and building a risk assessment system and analyzing the risk distribution are benefit of bridges operation departments to adopt appropriate risk control measures. And it has an important significance for reducing the risk of bridge operation and improving the overall safety of the bridge during operation.

\section{Fuzzy clustering algorithm steps}

\subsection{Original data obtaining}

The objects been studied are supposed as $X=\left(x_{1}, x_{2}, \cdots, x_{n}\right), \quad$ the $\mathrm{i}$-th object consists of $\mathrm{m}$ indicators to characterize its properties, namely $x_{i}=\left(x_{i 1}, x_{i 2}, \cdots, x_{i m}\right)(i=1,2, \cdots, n)$, then the original data are represented as a matrix:

$$
X=\left[\begin{array}{rrrr}
x_{11} & x_{12} & \cdots & x_{1 m} \\
x_{21} & x_{22} & \cdots & x_{2 m} \\
\mathrm{M} & \mathrm{M} & & \mathrm{M} \\
x_{n 1} & x_{n 2} & \cdots & x_{m n}
\end{array}\right]
$$

\subsection{Standardization of data}

When dealing with practical problems, because the dimension and magnitude of the $m$ index data may be different, the larger magnitude indexes may have a more significant impact on the resulting classification in the calculation, while the impact of the smaller magnitude

\footnotetext{
${ }^{\text {a }}$ Corresponding author: 810562002@qq.com

(c) The Authors, published by EDP Sciences. This is an open access article distributed under the terms of the Creative Commons Attribution 
indexes may be too small to be looked. In order to eliminate the different impacts of data dimension and magnitude in comparison process, data should be converted appropriately. Then each index value is in the range of united values, the data comparison will be more meaningful. The mean and variance of $j$-th column in the matrix $\mathrm{X}$ are calculated, formula is shown in Eq. 1 and Eq. 2 and Eq. 3. [1]

$$
\begin{gathered}
x_{i j}^{\prime}=\frac{x_{i j}-\bar{x}_{j}}{s_{j}},(i=1,2, \cdots, n ; j=1,2, \cdots, m ;) \\
\bar{x}_{j}=\frac{1}{n} \sum_{i=1}^{n} x_{i j}, \\
s_{j}=\left[\frac{1}{n} \sum_{i=1}^{n}\left(x_{i j}-\bar{x}_{j}\right)^{2}\right]^{\frac{1}{2}}
\end{gathered}
$$

\subsection{Fuzzy similar matrix structuring}

Process of structuring a fuzzy similar matrix is also known as calibration, which is calculating statistic $\mathrm{r}_{\mathrm{ij}}(\mathrm{i}, \mathrm{j}=1,2, \cdots, \mathrm{n})$ to measure the degree of similarity between the analyzed data, thereby the fuzzy similar matrix $\mathrm{R}$ which expresses similar relationship is established.

$$
R=\left(r_{\mathrm{ij}}\right)_{\mathrm{n} \times \mathrm{n}}=\left[\begin{array}{cccc}
r_{11} & r_{12} & \mathrm{~L} & r_{1 n} \\
r_{21} & r_{22} & \mathrm{~L} & r_{2 n} \\
\mathrm{M} & \mathrm{M} & & \mathrm{M} \\
r_{n 1} & r_{n 2} & \mathrm{~L} & r_{n n}
\end{array}\right]
$$

$r_{i j}$ is calculated as Eq. 4 and Eq. 5:

$$
\begin{aligned}
& r_{i j}=1-c d\left(x_{i} x_{j}\right),(i, j=1,2, \cdots, n) . \\
& \mathrm{d}\left(\mathrm{x}_{\mathrm{i}}, \mathrm{x}_{\mathrm{j}}\right)=\left[\sum_{\mathrm{k}=1}^{\mathrm{m}}\left(\mathrm{x}_{\mathrm{ik}}-\mathrm{x}_{\mathrm{jk}}\right)^{2}\right]^{\frac{1}{2}}
\end{aligned}
$$

Wherein, $\mathrm{c}$ is parameters which is chosen to satisfy $0 \leq r_{i j} \leq 1, d\left(x_{i}, x_{j}\right)$ represents the distance from $x_{i}$ to $x_{j}$ [2].

\subsection{Fuzzy equivalent matrix structuring}

Fuzzy clustering analysis requires that matrix to be analyzed satisfies the requirements: reflexive, symmetric, and transitive [3]. To make the matrix $\mathrm{R}$ transitive, it is needed to make the following changes: Starting from the matrix $\mathrm{R}$, square in turn $\mathrm{R} \rightarrow \mathrm{R}^{2} \rightarrow \mathrm{R}^{4} \rightarrow \cdots$, when $\mathrm{R}^{\mathrm{k}} \cdot \mathrm{R}^{\mathrm{k}}=\mathrm{R}^{\mathrm{k}}$ first appears, it is considered fuzzy matrix $\mathrm{R}^{\mathrm{k}}$ transitive, then fuzzy equivalent matrix $\mathrm{R}^{*}=\mathrm{R}^{\mathrm{k}}$ [4].

\subsection{Dynamic Clustering}

Dynamic clustering is conducted by using transfer closure method which is based on fuzzy equivalence relation. That is, when the fuzzy equivalent matrix element values $\lambda\left(\lambda \in R^{*}\right)$ declines from 1 to 0 , the category finally is classified as a class, which is a dynamic clustering process.

\section{Evaluation index system establishing}

\subsection{Risk indicators description and quantification of operation departments}

The following indicators are mainly considered in risk quantification of the operation departments:

\subsubsection{Description and quantification of security managers}

Bridges operation companies should set up safety management departments to manage the bridges overall safety, other operation departments should select full-time in charge of operation safety [5]. The number of safety managers in each departments has a direct impact on the effect of safety management; the quantification method is counting "the number of" the full-time safety managers in operation management departments.

\subsubsection{Description and quantification of safety training}

Safety training can increase safety knowledge of employees and improve safety management level of managers. There are many safety training methods, such as propagandizing road transportation safety laws or regulations and accident cases, etc. [6]. The quantification method for safety training is calculating the ratio of personnel who participates in safety training and the total number of each department personnel, namely "security training rate", units: "\%". 


\subsubsection{Description and quantization of fire alarm detection system}

Most of bridges operation management departments locate in different office locations and fire alarm detection system is an effective way to prevent and control office fires, so it has a direct impact on the safety of bridges operation management departments. The quantization method for fire alarm detection system is: assigning a value based on the effectiveness of each department's fire alarm system. Ineffective is "1"and effective is "2".

\subsubsection{Description and quantization of fire-fighting equipment and facilities}

The effectiveness of fire-fighting equipment and facilities is an important factor to measure the operation safety risk of each department. The quantization method for fire-fighting equipment and facilities is calculating the ratio of each department firefighting equipment and facilities coverage and the total area of the department, namely "firefighting equipment and facilities coverage rate", units: "\%".

\subsubsection{Description and quantization of hazard sources}

Hazard sources are important part of the bridges operation risk; each management department should identify and assess regular hazard sources and develop control measures according to the assessment results. The quantification method of hazard sources is identifying "the total number of hazard sources" of each department by using the same hazard identification methods.

\subsubsection{Description and quantization of the high-grade hazard sources}

High-grade hazard sources are the main threat to each bridge management department. The quantification method of high-grade hazard sources is identifying "the total number of high-grade hazard sources" of each department by using the same hazard identification methods.

\subsubsection{Description and quantization of safety activities}

Bridges operation departments can effectively improve the safety awareness of employees and increase the level of safety management by holding periodic safety activities and publicizing safety knowledge. The quantification method of safety activities is counting the annual average number of holding safety activities times. Units: "times / year".

\subsection{Construction of evaluation system}

Based on the above analysis, "A-safety management risk of operation departments" is set as evaluation target layer for safety management risk assessment. Factors layer are "A1-Number of safety managers"; "A2-Safety training rate"; "A3- Effect of fire alarm detection system"; "A4-Firefighting equipment and facilities coverage rate"; "A5-Total number of hazard sources"; "A6-Total number of high-grade hazard sources"; "A7-Safety activities". Evaluation System is detailed in Figure 1.

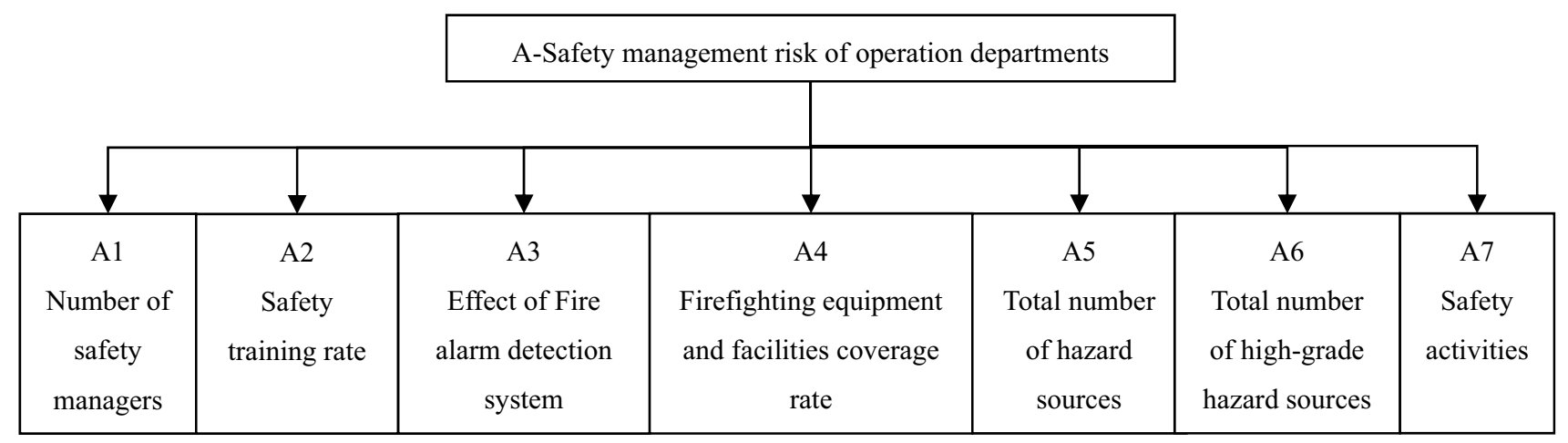

Figure 1. The whole safety risk assessment system of bridges during operation 


\section{Operation safety risk assessment of Taizhou Bridge}

\subsection{Evaluation target selecting}

Frontline operation management departments are chosen to assess safety risk of Taizhou Bridge. The assessment includes each toll station; service area and production scheduling center along Taizhou Bridge; repairing department; troubleshooting departments; equipment maintenance center and departments which directly relate to the bridge operation management. Evaluation targets are shown in Figure 2.

\subsection{Evaluation data obtaining}

According to the indicators (A1 A7) which relate to the risk of Taizhou Bridge management departments, research about 13 departments (K1 K13) of Taizhou Bridge is conducted and internal data are referred. Safety situation of operation management in 13 departments is quantized and the original data are obtained as Table 1 shows.

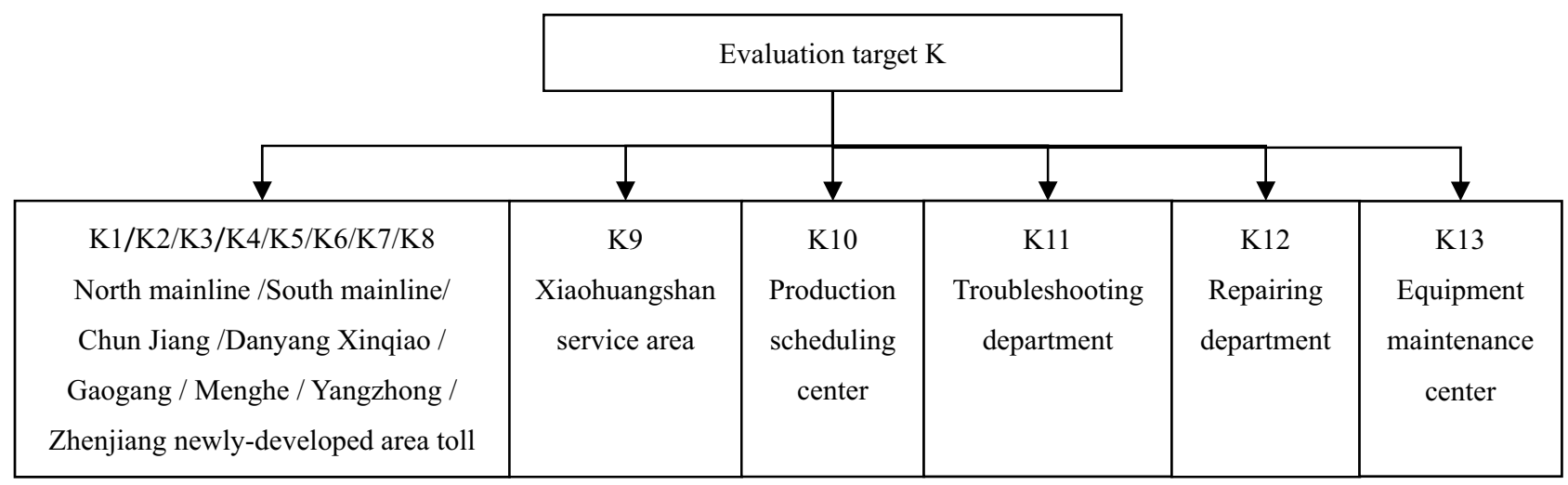

Figure 2. Internal management risk assessment object of Taizhou Bridge

Table 1. Original data collection of safety situation for 13 departments of Taizhou Bridge

\begin{tabular}{|c|c|c|c|c|c|c|c|}
\hline & $\mathrm{A} 1$ & $\mathrm{~A} 2$ & A3 & A4 & A5 & A6 & A7 \\
\hline $\begin{array}{l}\text { Risk } \\
\text { Research } \\
\text { objectives }\end{array}$ & $\begin{array}{c}\text { Number of } \\
\text { safety } \\
\text { managers }\end{array}$ & $\begin{array}{l}\text { Personnel } \\
\text { safety } \\
\text { training } \\
\text { rate[\%] }\end{array}$ & $\begin{array}{l}\text { Effect of } \\
\text { fire alarm } \\
\text { detection } \\
\text { system }\end{array}$ & $\begin{array}{l}\text { Firefighting } \\
\text { equipment } \\
\text { and facilities } \\
\text { coverage } \\
\text { rate[\%] }\end{array}$ & $\begin{array}{c}\text { Total } \\
\text { number of } \\
\text { hazard } \\
\text { sources }\end{array}$ & $\begin{array}{c}\text { Total } \\
\text { number of } \\
\text { high-grade } \\
\text { hazard } \\
\text { sources }\end{array}$ & $\begin{array}{c}\text { Safety } \\
\text { activities } \\
/ \text { [times/year] }\end{array}$ \\
\hline $\mathrm{K} 1$ & 3 & 95 & 2 & 90 & 72 & 2 & 24 \\
\hline $\mathrm{K} 2$ & 3 & 95 & 2 & 85 & 93 & 1 & 28 \\
\hline K3 & 1 & 70 & 1 & 70 & 79 & 3 & 10 \\
\hline K4 & 1 & 75 & 1 & 72 & 92 & 4 & 12 \\
\hline K5 & 2 & 82 & 2 & 75 & 85 & 3 & 18 \\
\hline K6 & 1 & 85 & 2 & 83 & 86 & 4 & 20 \\
\hline K7 & 1 & 75 & 2 & 84 & 62 & 6 & 14 \\
\hline K8 & 1 & 78 & 2 & 70 & 83 & 3 & 12 \\
\hline K9 & 2 & 78 & 2 & 73 & 174 & 3 & 20 \\
\hline K10 & 2 & 83 & 1 & 85 & 15 & 1 & 8 \\
\hline K11 & 1 & 85 & 2 & 65 & 28 & 1 & 10 \\
\hline K12 & 1 & 76 & 2 & 70 & 42 & 2 & 8 \\
\hline K13 & 1 & 78 & 1 & 68 & 16 & 1 & 12 \\
\hline
\end{tabular}

Note: “A5-Total number of hazard sources"and“A6- Total number of high-grade hazard sources" are derived from the internal report " Hazard sources identification and assessment report in operational phase of Taizhou Bridge " [7]. 


\subsection{Assessment analysis}

The data in Table 1 are converted into the form of a matrix and the above-mentioned fuzzy clustering algorithm steps are used to assess safety risk of Taizhou Bridge operation departments. For a more clear analysis of clustering results, Figure 3 is plotted to do further analysis on the dynamic clustering process.

It can be seen from Figure3: When $\lambda=0.93, \mathrm{~K} 1$ and $\mathrm{K} 2$ are first classified as a category; When $\lambda=0.89, \mathrm{~K} 5$ and $\mathrm{K} 9$ are classified as a category; When $\lambda=0.84, \mathrm{~K} 6$ and $\{\mathrm{K} 5, \mathrm{~K} 9\}$ are classified as a category; When $\lambda$ $=0.8307, \mathrm{~K} 8$ and $\mathrm{K} 12$ are classified as a category; When $\lambda=0.8284, \mathrm{~K} 7$ and $\{\mathrm{K} 5, \mathrm{~K} 9, \mathrm{~K} 6\}$ are classified as a category; When $\lambda=0.77, \mathrm{~K} 3$ and $\mathrm{K} 4$ are classified as a category; When $\lambda=0.74, \mathrm{~K} 10$ is added to the aforementioned category; When $\lambda=0.44, \mathrm{~K} 13$ is also added to the aforementioned category, thereby all the departments form a category.

From dynamic cluster analysis process and analysis, it can be seen that the risk level of the Taizhou Bridge operations departments $(\mathrm{K} 1 \sim \mathrm{K} 13)$ is $\{\mathrm{K} 1, \mathrm{~K} 2\}<\{\mathrm{K} 5, \mathrm{~K} 9\}$ $<\{\mathrm{K} 6\}<\{\mathrm{K} 8, \mathrm{~K} 12\}<\{\mathrm{K} 7\}<\{\mathrm{K} 3, \mathrm{~K} 4\}<\{\mathrm{K} 11\}<$ $\{\mathrm{K} 10\}<\{\mathrm{K} 13\}$.

It can be seen from Figure 3: When $\lambda=0.8307, \mathrm{~K} 8$ and $\mathrm{K} 12$ are classified as a category; When $\lambda=0.8284$, $\mathrm{K} 7$ and $\{\mathrm{K} 5, \mathrm{~K} 9, \mathrm{~K} 6\}$ are classified as a category; strictly speaking, the operational risks $\{\mathrm{K} 8, \mathrm{~K} 12\}<$ $\{\mathrm{K} 7\}$. Since the difference in value 0.8307 and 0.8284 is small, that in the actual management the risk difference can be ignored.

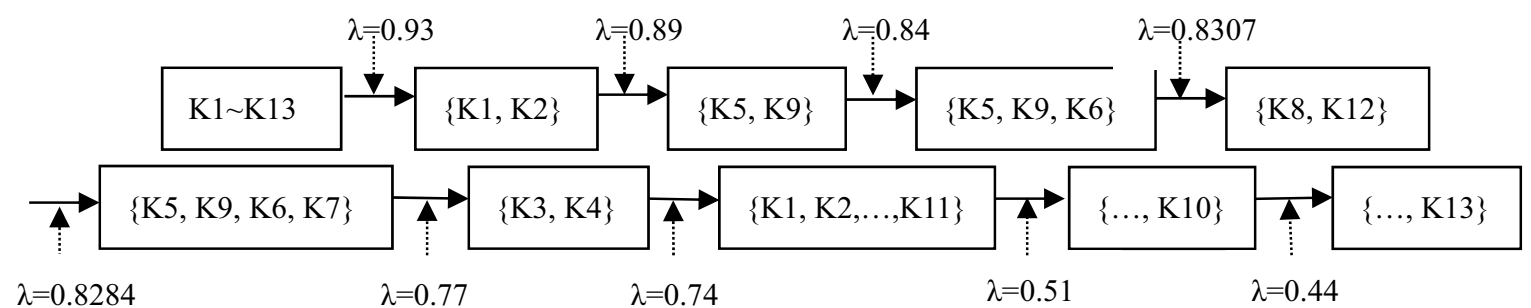

Figure 3. Further analysis of dynamic clustering of Taizhou Bridge (K1 K13 departments)

\section{Conclusions}

From the above analysis it can be seen: in Taizhou Bridge operation departments K1 K13, high-risk departments are troubleshooting department, production scheduling center and equipment maintenance center. As these departments are mainly responsible for road-block removing, inspection scheduling and equipment maintenance and repairing across the board in Taizhou Bridge, there are more persons, vehicles and other electrical equipment Etc., the risk level is higher. Accordingly, the assessment results match the actual operation situation.

\section{References}

1. Xie Jiping, Liu Chengping, Fuzzy mathematics and its applications, Wuhan, 2000.

2. Gao Xinbo, Fuzzy cluster analysis and its application, Xi'an, 2004.
3. Jiang Zejun. Fuzzy Mathematics tutorials, Beijing, 2004.

4. Wu Fubao, Li Qi. Delivery Methods of Fuzzy Clustering Analysis, J. Journal of Southeast University, Natural Science. 29(2) (1999) 105-110.

5. Yan Weiwen, Zhang Wenhai WANG Lei, Chen Guohua. Present Status of Quality of Safety Personnel in Enterprises and Suggestions on Their Training, J. China Safety Science Journal, 16(10) (2007) 51-55.

6. Dun Xuhua, Li Shouzhao. Function of Case Teaching and Discuss Teaching in the Safety Training Job, J. Journal of Safety Science and Technology, 2(1)(2006)95-97.

7. Hazard sources identification and assessment report in operational phase of Taizhou Bridge, R. Nanjing, Jiangsu Academy of Safety Science and Technology, 2014. 